\title{
Psychological and pedagogical support of the educational process: synergetic approach
}

\author{
Nadezhda Revyakina and Elena Sakharova* \\ Don State Technical University, 344002, Rostov-on-Don, Russia
}

\begin{abstract}
In this article, the process of linguistic faculty students teaching using innovative digital technologies is investigated in the focus of a synergetic approach. This problem is very relevant today, since the issue of preserving the quality of knowledge when implementing intensive electronic methods of mastering communication skills in a foreign language does not lose its actuality. Synergetics as the science of complex systems is now recognized as a new scientific paradigm in the study of various objects and processes. The authors focus on the features of the synergetic approach to the education process. From the point of view of synergetics, the authors consider the process of teaching foreign languages as a holistic dynamic system capable of self-organization and selfdevelopment. E-learning courses, which have become particularly popular in modern conditions, are considered as an integral part of the educational system. We are talking about self-organization of both the educational process and its structure, which is a means of optimizing students' learning, and activating students in order to ensure a high-quality learning process. The role of the teacher and psychological and pedagogical support of students in the learning process is emphasized. The authors note that the synergetic interpretation of the psychological and pedagogical approach to teaching students the basics of language based on digital technologies contributes to the personal growth of students and the development of a holistic dynamic system.
\end{abstract}

\section{Introduction}

The electronic environment evolution in the new millennium dictates global social changes. The rapid growth of information communication technologies contributes to the active real world virtual-spatial development. Information is given in incredible volumes, and its selection, analysis and synthesis greatly contribute to the development of students' cognitive abilities and personal growth.

The relevance of the research is due to the need for a systematic analysis of the selforganization process and the actualization of psychological and pedagogical support of the education as a complex dynamic system of students' speech-thinking activity. Mastering new information technologies requires improving the skills of working with not only complex computer programs, but also with new competencies. The student needs some

\footnotetext{
* Corresponding author: elenasakharova@bk.ru
} 
reorganization in connection with the development of computer technology as one of the main ways of developing communication skills and abilities.

There is a rethinking of the goals and results of the teaching process, which leads to the change in the research paradigm in science. To achieve greater success, science is moving into an interdisciplinary field, to convergent knowledge $[1,2]$. Convergent approach is built on the ideas of cooperation and development in accordance with the principle of complementarity, interdependence of nature and society, the development of creativity and innovation, as well as a holistic systematic approach, when specialists from various fields participate in scientific dialogue [3].

When several subject areas approach each other, a complex and deeper description of different phenomena of the surrounding world, including social ones, is obtained. All these processes are united by a synergistic paradigm in science, which is increasingly manifesting itself in research. Outstanding scientists have been actively developing this direction, which ensures the integrity of the transmission and perception of information [4-7].

H. Haken defined synergetics as the science of the actions of connected substructures in a nonlinear open system [8,9]. He believed that synergetics could explain the multidimensionality of the existing world. Synergetics considers any object or phenomenon as a complex nonlinear system that functions and develops with the coordinated interaction of all subsystems included in it. Chaotic movements within the system itself (fluctuations) cause the possibilities of self-organization, and individual parameters can undergo rapid abrupt changes, leading to chaos within the system (bifurcation), as a result of which the system itself evolves (self-organization), i.e. acquires new quality, is supplemented with new elements, follows a new path of its development [8].

The presence of such an object of research as an open nonlinear dynamical system allows the use of synergetics in various fields of both natural science and humanitarian cycles. In this case, synergetics acts as an interdisciplinary language and methodology of modern science.

The purpose of this article is to substantiate the application of synergetic analysis to the peculiarities of education process. We consider it relevant to apply an integrated synergetic approach to the process of teaching foreign languages. This issue turned out to be especially relevant during a pandemic, when the learning process turned into a distance format and required psychological and pedagogical support.

\section{Method}

The synergistic approach is successfully applied in the educational and pedagogical sphere [10-13]. It should be noted that the backbone elements of this approach are rather multidimensional. They represent not only communication within the framework of statusrole relationships, but also a number of skills and abilities that lead to the formation of the personality's new competencies and self-development. The purpose of educational discourse has a multi-level nature: from the formation of basic general cultural competencies to the full socialization of the individual in society. We should not forget about the formation of a would-be professional capable of giving an adequate selfassessment of his cognitive activity.

The main goal of the educational process is to create conditions for the comprehensive development of trainees in all the variety of psychophysical, social and personal characteristics of each individual. The effectiveness of educational discourse can be an important indicator of the teaching process quality.

The pedagogical discourse has an informational, semiotic, anthropological and cultural origin; it is viewed not only as a product, but also as a goal of learning in the new conditions of the prevalence of information technologies based on a synergetic paradigm. 
Changing social environment dictates the need for this transformation. The success of psychological and pedagogical influence is associated with the personal qualities of the subjects of the educational process. The necessary mechanisms for the transformation of educational discourse are both reflexive mechanisms of personality development and the developmental activity itself in an innovative social and educational environment.

The pedagogical discourse values are presented in the strengthening of social traditions. The positive result of pedagogical interaction is largely determined, according to scientists, by the communicative and creative potential of the teacher's personality, his communicative abilities aimed at creating comfortable conditions for student self-development.

The communicative strategy of interaction between teachers and student is much more successful when Internet technologies that make a creative atmosphere for the development of active cognitive activity are used [14]. This partnership tactic is one of the main trends in the main strategy of the entire educational process, in which the key concepts of synergy self-organization and management -are interpreted as self-education and self-government. With this approach, great importance is attached not only and not so much to the subject content of the discipline. It is becoming more and more relevant to teach students various ways of self-organization, self-education. It is of more importance to teach them how to use methods of self-acquisition of knowledge: finding the necessary information, the ability to process, analyze and interpret it $[15,16]$.

The process of self-organization leads a student to self-reflection, dialogue with himself and, as a result, to the analysis of his abilities, intentions and capabilities. A non-linear situation arises in which the inner choice of the individual, the choice of value attitudes is carried out more effectively, and the perception of the situation itself becomes qualitatively different, deeper and more versatile. All of the above mentioned contributes to the manifestation of the students' creative abilities. From the point of view of a synergistic approach, the role of the teacher is reduced to observing the students' reasoning and switching the learning process from one level to another. In this regard, incentives for learning are created largely not only by the teacher, but also by the collective actions and energy of the group.

The goal of education in the focus of synergetics is the continuous development of the personality, its synergetic culture. Consequently, it is necessary to promote the development of a modern worldview that adequately reflects the state of the socio-natural system, the relationship "man-society-nature-cultural sphere". We should not forget about the development of intellectual abilities to solve global problems. All these factors contribute to the self-organization of the student's personality, fostering a responsible attitude of young people to the world around them.

The objectives of synergetic education are:

- acquiring knowledge about the unity of nature, society and man;

- acquisition of main human problems, ways and means of their solution;

- development of intellectual and practical skills to study;

- education of personal value orientations, his motives, needs, habits of eco-logically and culturally appropriate behavior;

- activity aimed at the coordinated development of man, society and nature;

- strengthening of abilities for nonlinear analysis of non-standard situations, alternative thinking in the choice of methods of resolution;

- formation of a non-linear style of thinking, a personal attitude to the world around, the ability to navigate in a rapidly changing technologized world;

- integration of natural science and humanitarian culture aimed at understand-ing and solving common human problems;

- learning the techniques of synergetic analysis, forecasting and modeling the evolution of a specific phenomenon, where social and natural factors interact. 


\section{Research}

As for the process of teaching foreign languages, from the point of view of synergetics, it is considered as a process of managing students' self-learning [17, 18, 19]. The process of teaching a foreign language is a holistic systemic education that includes a variety of teaching methods and technologies. Methods are changing, improving. Teachers are looking for new and effective ways to teach students. However, there is no doubt that teaching foreign languages in modern conditions is impossible without the use of distance technologies. These technologies are actively being introduced into the educational process, becoming its integral part, a subsystem, which also affects the activity of the entire system and its result.

One of the varieties of distance technologies are electronic learning courses, which have become especially in demand in the higher education system. In this process, a very important role is played by special e-learning courses made by teachers in both theoretical and practical disciplines.

The learning courses in distance learning are rather heterogeneous, since the teachers who create these courses are focused on groups of students of various directions and training profiles.

However, it is possible to highlight the following features inherent in the created ecourses [19]:

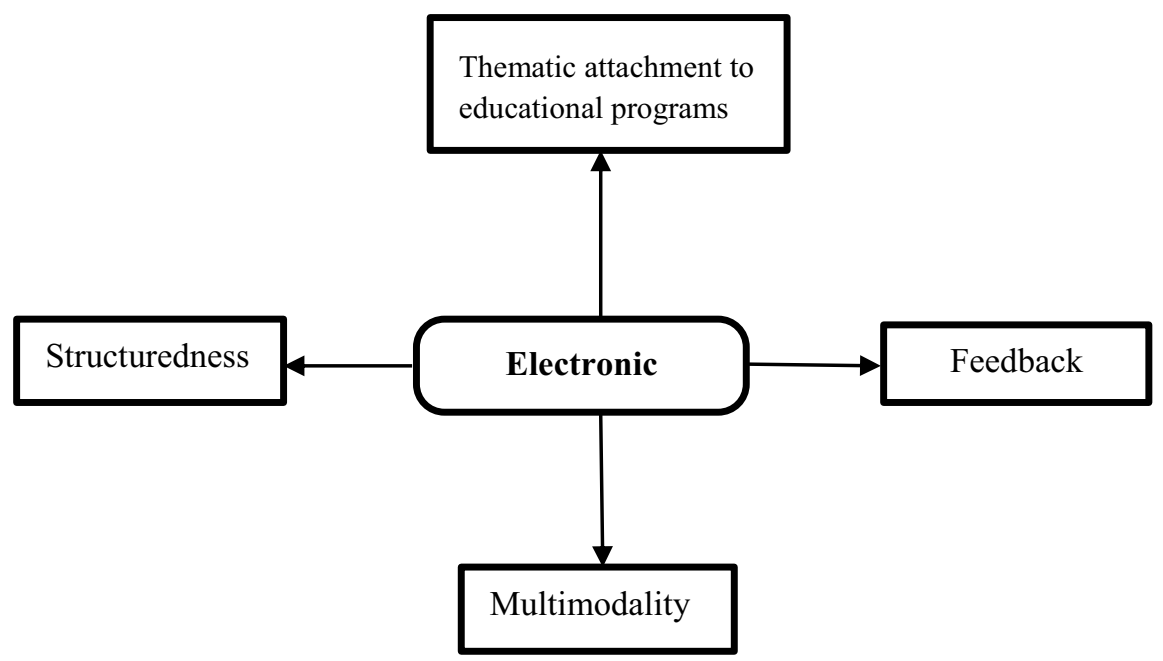

Fig. 1. Typical features of the electronic courses

- Thematic attachment to educational programs and disciplines is the basic characteristic of the courses.

- Then comes such element as structuredness: courses consist of sections that include annotations, recommendations for working with the course, thematic selection of texts, grammar material, exercises and tasks for working out vocabulary and grammar, test tasks.

- Multimodality is the next necessary feature of the courses that means the material is offered in various modes: text documents for reading, analysis and translation, audio files for listening, videos, presentations, links for educational materials on other sites and platforms. This organization of the course makes it possible to diversify the material and forms of activity in the classroom, makes them more interesting and productive, develops the independence and creative abilities of students. 
- In this regard, one should also not forget about feedback: in the structure of the course, a section is allocated for students to complete tests and various creative tasks with the ability to comment and give marks for the work.

The analysis of the created for teaching students a foreign language courses' allows to conclude that the materials (texts in print, as well as in audio and video formats) are of the informational, feature, journalistic and analytical direction. There is also a news mode of presenting information. The choice of material required for foreign language classes is determined by the specifics of the educational sphere and the content of the subject.

E-learning courses for studying a foreign language for students of various specialties are designed in such a way that student can feel the inextricable connection of the material presented in the course for distance learning with future professional activities.

The educational material presented in electronic courses in a foreign language contains professionally oriented information, as well as algorithms for working with special texts. The information from professional spheres in a foreign language is accompanied by various kinds of tasks encouraging students to talk about the topic concerned. This contributes to the development of general and professional skills that will be useful in practical activities.

The e-learning course is a kind of conductor between the subjects of communication. It performs a number of important functions: it allows the teacher to keep in touch with students in the classroom and beyond it. The pragmatics of electronic courses allows you to manage the educational process, build differentiated interaction with students. It contains the necessary material for the practical development of foreign language, both for working in a group online and for independent training of students. It allows the teacher to control the knowledge of the students.

Thus, electronic courses of a discipline within the framework of pedagogical discourse are the result of self-organization of the system, its evolution. They are included in the educational process as a new system parameter that determines the continuous and effective functioning of the entire online learning system.

Of course, electronic courses of the discipline cannot and should not replace an autonomous educational process and communication between a teacher and students. However, in a pandemic situation, such a new component in the system of educational and pedagogical discourse is quite appropriate.

\section{Conclusion}

In conclusion, we will summarize the results of this study. Synergetic ideas are a trend in modern science; they are rapidly penetrating into all spheres of human life including education. If at first it happened mechanically, today scientists are optimistic about the prospects for a synergistic approach in the educational process. The educational process from the point of view of synergetics is an open non-linear dynamic system consisting of a set of its elements - internal subsystems. All elements of the system follow a single global goal, interact with each other and depend on each other. The openness of the educational system allows it to form new subsystems in a crisis to ensure its effectiveness.

Electronic learning courses in the foreign languages can be considered as an example of such a subsystem. In a situation of instability in the framework of distance education, they are highly in demand and in some cases indispensable. E-courses perform important functions for the transfer of information, the development of certain skills and the control of knowledge, thereby ensuring the continuous and effective operation of the educational system.

The main task of a foreign languages teacher is to help students in self-organization, development of basic strategies for self-education, formation of algorithms for extracurricular work to master new knowledge. The choice of strategies for personal growth 
in the study of a foreign language is determined by individual psychological characteristics, cognitive needs, commitment, and initiative of students.

\section{References}

1. M. Lundstrom, H.S. Wong Philip, Technology and Society. Science Policy Re-ports. Springer, Cham. (2013). DOI: https://doi.org/10.1007/978-3-319-02204-8_1

2. M.C. Roco, W. Bainbridge, B. Tonn, G. Whitesides, Convergence of Knowledge, Technology and Society. Science Policy Reports. Springer, Cham. (2013). DOI: https://doi.org/10.1007/978-3-319-02204-8_10

3. O.E. Baksansky, Philosophy and Culture 7 (79), 1061-1068 (2014). DOI: https://doi.org/10.7256/1999-2793.2014.7.11995

4. S.C. Müller, P.J. Plath, G. Radons, A. Fuchs, Springer International Publishing, (2018). DOI: https://doi.org/10.1007/978-3-319-64334-2

5. V.G. Budanov, L.A. Aseeva, Anthropology archaeology history and philosophy medieval \& renaissance studies 2, 565-573 (2017). DOI: https://doi.org/10.5593/sgemsocial2017/22/S09.075

6. G. Buenstorf, Evolution, Organization and Economic Behaviour (Edward Elgar Publishing, 2012).

7. W. Tschacher, M. Tröndle, Futures 43, 1, 67-75 (2011). DOI: https://doi.org/10.1016/j.futures.2010.06.001

8. H. Haken, Secrets of Nature. Synergetics: Doctrine of Interaction (Institute of Computer Researches, Moscow-Izhevsk, 2003).

9. H. Haken, Biological and Sociocultural Evolution 15-24 (2019).

10. M. Petrenko, Procedia - Social and Behavioral Sciences 214, 407-413 (2015). DOI: https://doi.org/10.1016/j.sbspro.2015.11.690

11. N.S. Nikolaev, Bulletin of Cherepovets State University 4, 5-9 (2009).

12. S.D. Yakusheva, Synergetic approach in the development of professional skills of a modern teacher, XIII International scientific - practical Conference Part II. Novosibirsk, (2012). https://sibac.info/conf/pedagog/xiii/26949

13. K. Zeichner, Teaching and Teacher Education 21 (2), 117-124 (2005). DOI: 10.1016/j.tate.2004.12.001

14. S.V. Pervukhina, G.I. Radchenko, E3S Web of Conferences 210, 18036 1-10 (2020). DOI: https://doi.org/10.1051/e3sconf/202021018036

15. T.B. Mikheeva, E.V. Murugova, SHS Web 70, 07003 (2018). DOI: https://doi.org/10.1051/shsconf/20197007003.

16. J.S. Morozova, I.G. Kuzheleva, E3S, DOI: https://doi.org/10.1051/e3sconf/202021022026

17. N.V. Kurikova, E.Yu. Nadezhdina, Teaching Foreign Languages in the Synergetic Approach. Philological Sciences. Questions of theory and practice (Gramota, Tambov, 2013). 4 (22) Part II, 102-104 (2013). www.gramota.net/materials/2/2013/4-2/27.html

18. S.K. Gural, Self-developing System Procedia - Social and Behavioral Sciences 154, 3 7 (2014).https://doi.org/10.1016/j.sbspro.2014.10.103

19. E. Sakharova, N. Revyakina, E3S Web of Conferences 210, 18040 (2020). Innovative Technologies in Science and Education (ITSE-2020). DOI: https://doi.org/10.1051/e3sconf/202021018040 